\title{
Alternative Didactic Strategy to Link Teaching with Environmental Protection
}

\author{
Andres Eduardo Vera Mendoza*, Liceo Bolivariano Jose Jesus Osuna Rodriguez
}

Ministry of Popular Power for Education, National Public Institution, Santa Elena de Arenales, Venezuela

\author{
Email address: \\ andresvera983@hotmail.com (A. E. V. Mendoza) \\ *Corresponding author
}

\section{To cite this article:}

Andres Eduardo Vera Mendoza, Liceo Bolivariano Jose Jesus Osuna Rodriguez. Alternative Didactic Strategy to Link Teaching with Environmental Protection. Science Journal of Education. Special Issue: Educational Innovation “Teaching and Learning” Strategies. Vol. 7, No. 6, 2019, pp. 114-120. doi: 10.11648/j.sjedu.20190706.11

Received: September 16, 2019; Accepted: October 29, 2019; Published: November 5, 2019

\begin{abstract}
To link education with the protection of the environment and soils through a didactic, innovative and interesting strategy in the training and awareness process, the development of an agricultural Biol was carried out as an alternative to produce ecological fertilizers, low cost for the producer and institutions dedicated to producing different agricultural items, acting as an excellent foliar stimulant for the plants and a complete soil rejuvenator; with decomposing materials such as; manure, water, milk (liquid), chopped grass, molasses, organic humus (fertilizer) and minerals as a supplement, through a biodigester (Release of accumulated gases). Educational alternative in young people who are in the process of training in Secondary Education in Mérida Venezuela, given the indiscriminate use of chemicals that damage the planet, plants and soil. This article focuses on an action research, supported by a theoretical and practical teaching planning. As a result, relevant learning was obtained for the pedagogical and agricultural system, managing to focus students on acquiring new strategies and ideas, conserving and protecting the environment through cooperation, interest and motivation to recommend this alternative to other students, teachers and Farmers develop new fertilizers that benefit the different agricultural items and have healthy and quality food for human consumption.
\end{abstract}

Keywords: Education, Didactics, Environment

\section{Introduction}

Since man began on his land, the cultivation of a variety of crops and life in his crops showed that the soil was tired, the nutrients were depleting over time, so he chose to apply new measures aimed at recovering his productivity The first were: that the land rested after each harvest, the rotation of the fields destined for sowing and the obtaining of agricultural items, this is how in middle education the alternative of including theoretical and practical components in the process of teaching, thus expanding the capacity of young people in the agricultural area as a reflective approach to protect the environment.

Faced with this reality, teaching is the most important world where we can transform the human being; in it, adolescents have the opportunity to participate, integrate and analyze a teaching process where they must focus on learning new knowledge and then use them in field work as an alternative.

In this sense, the Lyceum becomes a place where young people are trained with different strategies considered important in the training process, in order to generate changes in the human being, from different levels and modalities that the pedagogical system offer, developing their own physical, psychic, cultural and social status to create the conditions of aptitude, vocation and aspiration to conserve the soil and items.

Consequently, the population has been increasing food needs, demanding that the land produce abundantly and permanently, since the results are weak lands with the need to improve their nutrients and obtain better crops. Hence the alternative to solve the problem by obtaining a homemade Biol "Liquid Fertilizer" that fulfills the functions of foliar stimulant and fertilizer for the soil, from organic biodigester wastes such as cattle manure, water, molasses, liquid milk, chicha, mineral components, chopped green grass and 
organic fertilizer (humus).

However, the development and application of agricultural Biol is a simple and practical technique that consists of two components: a solid and a liquid. The first is known as biosol and is obtained as a product of the discharge or cleaning of the biodigester where the Biol is made, the liquid part is known as foliar fertilizer where the solid residue is constituted by non-degraded organic matter excellent for the production of any crop.

That is, it allows to balance the nutrient content present in the soil, the plants grow remain healthy and resistant, offering abundant and quality products, reflecting in them the conservation of the environment and better health to the consumer through products brought from the field With ecological alternatives.

Similarly in the field of education and agriculture, it is considered important what is evaluated by other researchers and collect data that respond to the application of Biol and chemical fertilization in the rehabilitation of pastures in Pichincha, Ecuador. "He determined that the application of pure Biol and $75 \%$ acted positively" in the recovery of pastures for grazing purposes compared to the application of urea, and even more economically satisfied the investment made "[1].

It also describes the effect of cow manure, pig and guinea pig bioles on lettuce and cabbage crops in Colombia. The authors reported "that they did not find very significant differences between the applications of bioles and a commercial foliar fertilizer. Manure, pig and guinea pig "[2].

However, the conservation of the plants is reflected in the continuity of the growth of the shoots, fruits and leaves, which results in a greater foliar area to maximize the photosynthetic efficiency of the cultures through hormones that allow Stimulates cell division and with it establishes a "base" or structure on which growth continues. "The application of this natural fertilizer allows to balance the content of nutrients in the soil, plants grow better, remain healthy and resistant, their products are abundant and quality" [3].

Given this reality, it is important to incorporate into the educational system new innovative and interesting activities that focus on the current agriculture that Venezuela and the world lives, or what is the same, generate awareness in students and farmers, and become part of the Learning process in educational institutions, "putting into practice the new academic projects in the school system, thus applying new instructional strategies, achieving a more thoughtful, critical and protagonist student in each of the proposed Activities" by the [4].

In this sense, the pedagogical methods in secondary education in Venezuela "focus on the integral education of adolescents and young people, between approximately 12 and 19 years old, offering study alternatives, such as Bolivarian High Schools and Robinsonian Technical Schools" [5]. Have secondary schools as the main objective of the training and adolescents and young people with historical, potential and thinking skills, cooperative, reflective, liberating; and contribute to the solution of problems in the classroom and spaces destined for agriculture as a teaching, learning strategy.

This is where the master specialist in agriculture and endogenous development has the responsibility of integrating the classroom and the field destined to agriculture in the new pedagogical practices, that is to say to apply a planning with creative and transformative strategies that benefit the students in the secondary education general and be approached by other institutions that point to this type of alternative, becoming a space of understanding between teachers, students and farmers, full of new options and ideas to produce bioles that protect the natural environment. Hence the problem, where teachers rarely apply in their school programming new teaching strategies that allow them to be more interesting in their theoretical and practical activities in agricultural education, where the student expresses what he has acquired in his academic training and serves as aid or alternative taken into account by the producer in the different agricultural items in Venezuela and in the world.

\section{Purpose (s) Achieved in the Project; Preparation of the Agricultural Biol "Liquid Fertilizer"}

a) Motivate (25) young people from secondary education to develop a Biological product as an alternative to produce at a lower cost, conserve the environment, the soil and the items to be produced.

b) Know the rules of the experiment for compliance during the development of the activity.

c) Stimulate the students of the José Jesús Osuna Rodríguez Bolivarian High School in the state of Mérida Venezuela to learn new teaching strategies, learning through the theory and practice of the field in the agricultural area.

d) That the (25) young people know new alternatives when establishing their crops in the area and outside it for the benefit of our collective and the environment.

\section{Theoretical Argument}

However, education is considered within the teaching, learning process as a component where the human being, based on different perspectives, provides training opportunities for the human being. In this way, the documentary information, background, practices were gathered and for which the Agricultural Biol "Liquid Fertilizer" was prepared, and are described below:

What is an Organic Fertilizer: it is a fertilizer made from animal manure and plant residues that can be: solids (compost) and liquids (Biol). Why should we use organic or natural fertilizers? Because they are affecting the soils due to the indiscriminate use of chemical or agrochemical fertilizers, and it makes the production, every day less, and the presence of pests and diseases becomes uncontrollable 
and the lands or items become immune to the chemicals. This also increases production costs, pollutes the natural environment and is harmful to health. That is why it is essential to have a varied and complete fertilization program, as an alternative the use of natural fertilizers that protect and develop the life of microorganisms and improve the structure of the soil: that is, we give life to the soil, to the lands that produce a great variety of items in the fields of Venezuela and other parts of the world. [6]

Thus, the production of liquid fertilizer Biol is a relatively simple and low-cost process; its preparation inputs are local. Biol has two components: a solid and a liquid. The first is known as biosol and is obtained as a product of the discharge or cleaning of the biodigester where Biol is made, the liquid part is known as foliar fertilizer. The solid residue is constituted by non-degraded organic matter, excellent for the production of any crop [7].

In Biol we can use any type of manure. Applying this natural fertilizer allows to balance the content of nutrients in the soil, plants grow, remain healthy and resistant, their products are abundant and of quality. It also reflects soil conservation; better health as better products brought from the field will be consumed, preserving the environment [8].
Recommended for coffee production, it stimulates the development of foliage and flowering of the plant. This fertilizer gradually loses its effectiveness over time, should be used within the first three months of its preparation. Biol revitalizes plants that suffer stress, whether from pests, diseases or disruption of their normal development processes through timely, sustained and good nutrition, thus offering food free of chemical residues [9].

In fact, the elaboration of Biol is not necessary a recipe, we simply elaborate it with the residues that are around us, it stimulates and strengthens the development of plants, improves the production of fruits, the crops become resistant to the attack of diseases and adverse weather changes. For the aforementioned, a scheme can be visualized in a summary form. What is a Biol? And thus better understanding of it and interpretation [10].

\subsection{The Biol}

It is a liquid fertilizer that originates from the FERMENTATION of organic MATERIAL, as shown in the following figure: [11]

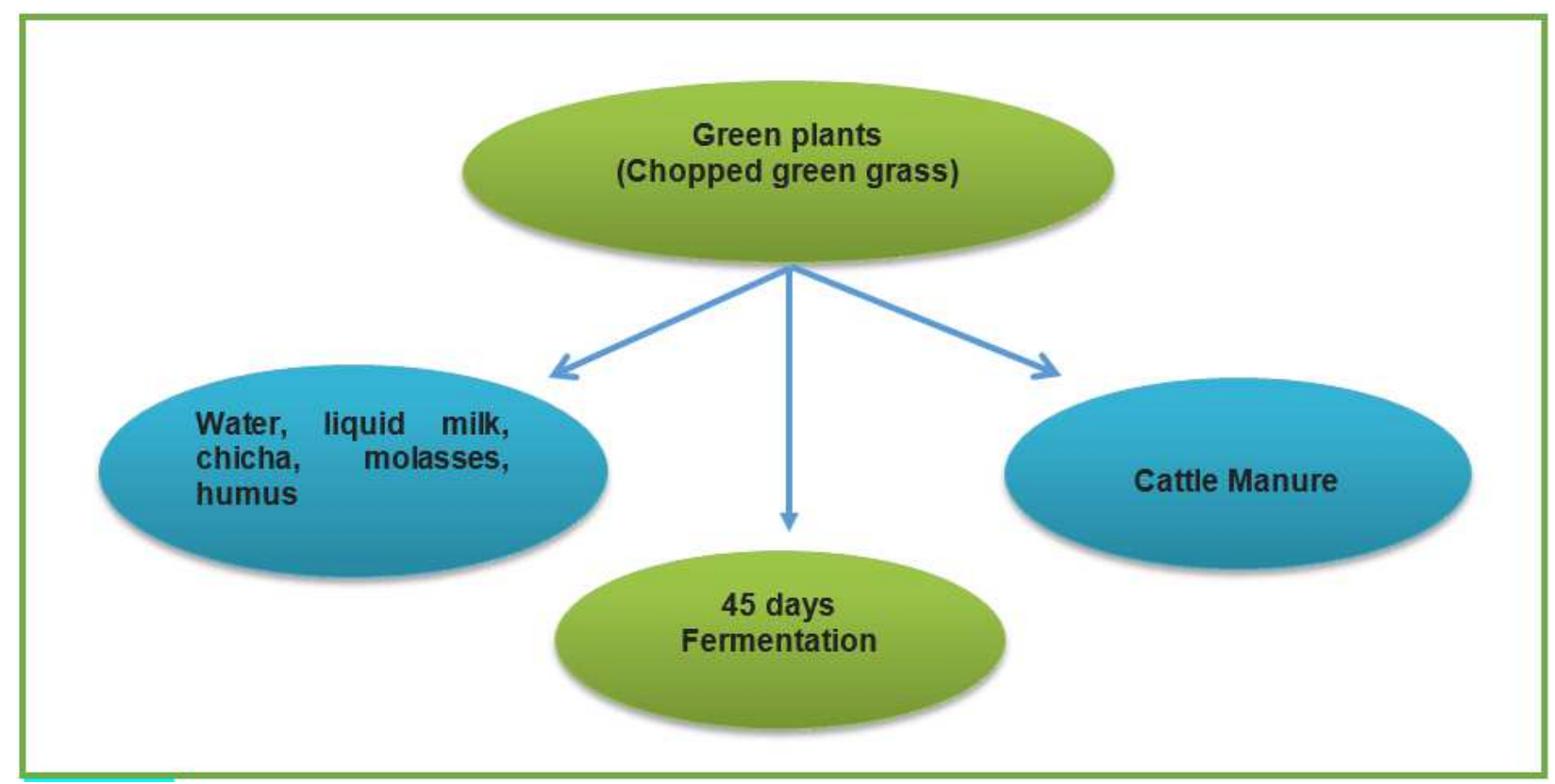

Figure 1. Material is decomposition.

\subsection{What Type of Organic Fertilizers Exists}

In this case they are classified according to the type of application or use. Some that are used directly to the ground and others that are applied in foliar form to the plants. The main organic fertilizers used are: [12]

a) Compost.

b) Earthworm humus.

c) Animal manure.

d) Green fertilizers.

e) Biofertilizers.

f) Bioles or foliar fertilizers, within them we have:
Supermagro, compost tea.

Of these organic fertilizers, Biol Supermagro is the one that is being developed and applied in the area of Santa Rosa, Menocucho and Catuay of the district of Laredo Ecuador, with good results in the production of strawberry, lettuce, radish, among other crops. All these theoretical demonstrations that give understanding to the development of natural Biol together with research done by other authors such as:

He evaluated the response to the application of Biol and chemical fertilization in the rehabilitation of grasslands in Pichincha, Ecuador. He determined that the application of 
pure and $75 \%$ Biol acted positively in the recovery of grasslands for grazing purposes compared to the application of urea, and even more economically satisfied the investment made [1].

"He visualized the effect of cow manure, pork and guinea pig bioles on lettuce and cabbage crops in Colombia. The authors reported finding no significant differences between the applications of the bioles and a commercial foliar fertilizer" [2].

The activity of the plants is reflected in the continuity of growth of the shoots and their leaves, which has a greater foliar area to maximize the photosynthetic efficiency of the cultures by means of hormones that allow to stimulate cell division and thereby establish a base or structure over which growth continues. Applying this natural fertilizer allows balancing the nutrient content in the soil, plants grow better, remain healthy and resistant, their products are abundant and of quality [3].

\section{Methodology}

The research that served as a basis for this article as a result of the indiscriminate use of agrochemicals, so that the research is framed in qualitative terms. Therefore, qualitative research is "the collection of data, analysis and interpretation that cannot be measured objectively, that is, it cannot be synthesized in the form of numbers. However, this does not imply a lack of objectivity of the results" [13]. So it is important to point out that in carrying out this type of research it leads us to interpret the data collected in the field in a more objective way for its interpretation of the results.

From a more general perspective, the research seeks to propose through the development of agricultural Biol, implement new learning strategies that are innovative, interesting recreational for the (25) students of the José Jesús Osuna Rodríguez Bolivarian High School, so that it makes sense of awareness and provide ideas that benefit the production of the different items of the agricultural field of the campus and producers of the Santa Elena de Arenales area of the state of Mérida Venezuela, preparing a more economical liquid fertilizer based on decomposing material, such as cattle manure which helps to take care of the environment, the soil and the health of consumers, in the face of indiscriminate use of agrochemicals.

In addition, qualitative research "is based on a rethinking of the subject-object relationship in that focus of the object of study directly where the problem lies. The dialectical integration of subject-object is the articulating principle of the entire epistemological scaffolding of research qualitative" [14]. In other words, it focuses on action research, because the data of interest is collected directly from reality by the researcher.

Also "are those that refer to the methods that will be used when the data of interest are collected directly from reality, through the specific work of the researcher and his team, these data obtained directly from the empirical nature, are called primary, since which are the product of research without intermediaries of any nature" [15].

However, we worked directly with young people of the second (2nd) year of secondary education, with an enrollment of (25) students who presented the following characteristics from 11 to 13 years of age, residents of the study area and one (1) Professor specialist in the area of education for work and endogenous development in education. These people make up the universe of the unit of analysis that served as a case study (case study intentional and unique).

In other words, a recipe is not necessary for the elaboration of Biol, it is simply transformed by applying and mixing different components that are in our field or different planting spaces, helping to stimulate and strengthen the development of plants, improve the production of fruits where crops become resistant to disease attack and adverse weather changes. By allowing balancing the content of nutrients in the soil, plants grow healthy and resistant being abundant and quality products.

\section{Results and Discussion}

Specify that it is possible to develop an agricultural Biol a natural product at a lower cost with material that is in our hands in the educational institution and in the agricultural field, such as: milk, chicha, molasses, chopped grass, water $(\mathrm{H} 2 \mathrm{O})$, mineral components between they sulfur, sulfate and cow dung.

Another achievement was to pack the product in 2-liter bottles for later application in the agricultural spaces of the Jose Jesus Osuna Rodríguez Bolivarian High School and producers as an alternative to apply in crops and use them as new teaching strategies in the classroom and in the field in the process of school training.

Another contribution was to improve the knowledge of the (25) young people of the Jose Jesus Osuna Rodríguez Bolivarian High School in the state of Mérida Venezuela, hence the farmers resume this type of activity and strategy as an alternative to produce natural, homemade, healthier and cheaper fertilizers to apply in articles consumed by the population, protect our environment, soil and consumer health.

Similarly, students learn to change their skills and actions to preserve the environment and our educational environment to be more aware of the indiscriminate use of agrochemicals in the field destined to plant products in Venezuela.

A greener product was also achieved to be presented to the producers of the Obispo Ramos de Lora Municipality, Mérida state, Venezuela. After obtaining and applying the agricultural Biol, the didactic and academic process is strengthened by applying new learning strategies in the agricultural subject with the help of the tasks of beginning, development and closing of the pedagogical planning, helping to conserve the soil, the planet, health, this allowed an active participation of students in the design and development of the product. 


\subsection{Beginning of the Practical Activity in the Classroom and Field}

Table 1. Ingredients and minerals.

\begin{tabular}{ll}
\hline Basic ingredients & Minerals List \\
\hline Fresh manure 10 Kilos & Sulfur 01 kilo \\
Water 10 Liters & Sulfate 01 kilo \\
06 Liter Milk & \\
Molasses 04 kilos & Mineral supplement 01 kilo \\
Chicha 03 Liters & \\
\hline
\end{tabular}

Then you choose a place without slope and clean, it must be a safe space, out of reach of children, animals or other people outside the site selected to work. Place the 10 liter drum in a place of ease for product movements. Subsequently add sulfate, sulfur and the corresponding minerals in quantities of $250 \mathrm{gr}$.

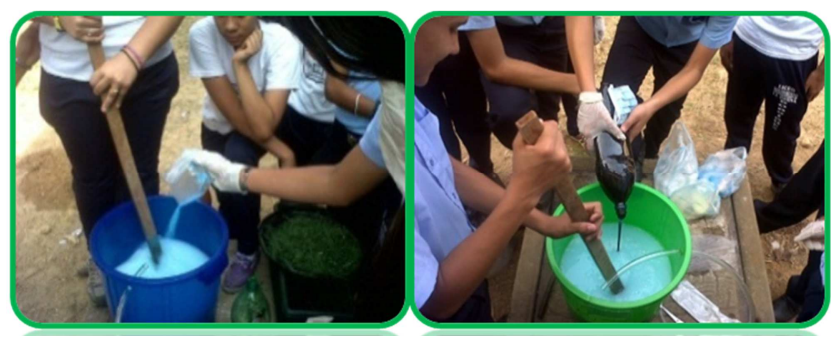

Figure 2. Material used in the Agricultural Biol.

It should be noted, that, the students were answering during the fertilizer preparation the questions asked. And so some brainstorming of the master specialized in agriculture and endogenous development explaining the appropriate method for the development of the experiment "Agricultural Biol" that gives starts the objectives planned in the didactic action and the students are clear at the time of the execution of the activity.

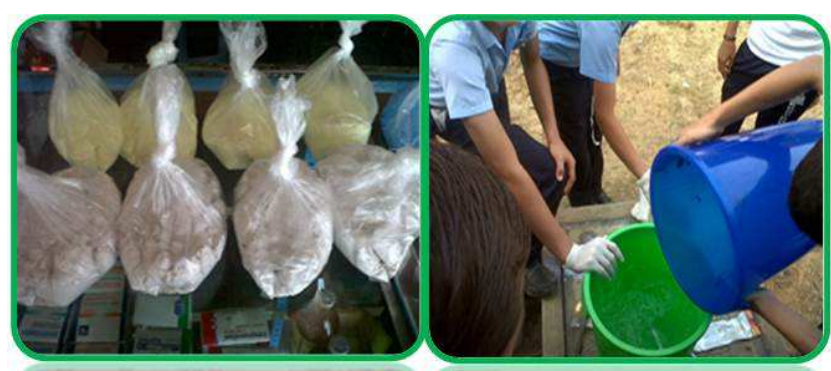

Figure 3. Material applied in the Agricultural Biol.

\subsection{Development and Preparation of the Agricultural Product}

The elaborated Biol is an encouraging part for (25) students to learn through new teaching strategies, they are trained through other alternatives that will be used in the field, in this way to comply with the procedures in the preparation and application of agricultural Biol as natural liquid fertilizer.

Then the product was developed with the guidance of the teacher and the participation of the students after completing the initial phase, the organization of work groups for the development of Biol as part of the learning process in the field of work, assuming the responsibility to improve and protect the environment, the soil, the plants and the elements produced by the farmer.

It all starts with the drilling of the container to install the $3 / 8$ "hose that serves as a biodigester to release the accumulated gases in the Biol container, adding each of the ingredients in the required container such as water, liquid milk. Molasses, chicha, minerals, cattle manure, humus (organic fertilizer), grass, chopped grass and stir until a homogeneous sample are obtained. All these actions can be observed in the photographs taken during the development of the experiment with the help and guidance of the specialist teacher and the integration of learners.

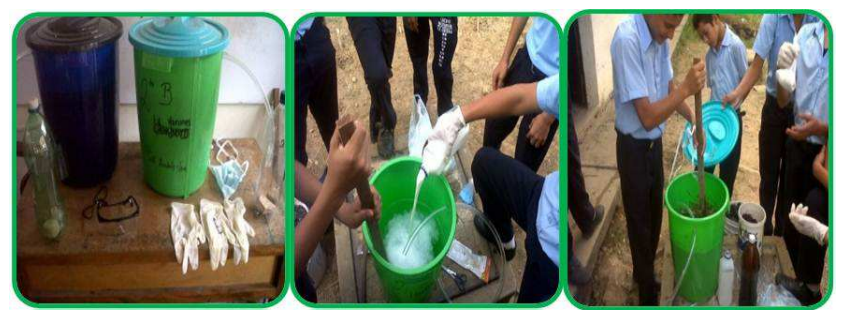

Figure 4. Material applied in Biol.

Every 3 to 5 days one of the minerals is dissolved in 1 liter of water and 1 liter of molasses, 1 liter of chicha, 1 liter of milk and a supplementary ingredient is added to the mixture, until 30 liters are completed. Subsequently, it is left to ferment for 30 days up to 45 days depending on the weather conditions.

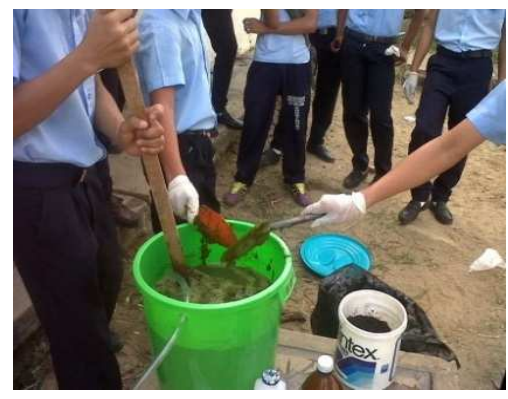

Figure 5. Casting to prevent residues from entering.

Move the Biol before adding the ingredients, this baby procedure should be performed every three to five days as shown in figure number 5.

\subsection{Closure of the Activity, Packaging of Agricultural Biol Products}

As a closing stage, the liquid fertilizer was carried out, the product is packaged in containers of (2) liters, labeled for identification and subsequent application to some crops (YES) others (NO) in the field for agriculture in the institution Public Liceo Bolivarian Jose Jesus Osuna Rodríguez located in the state of Merida Venezuela.

Likewise, a type of group discussion was applied in the 
classroom and the spaces reserved for agriculture, projecting a favorable learning in the teaching of agronomy and important contributions to the educational system through new ideas for the teaching and awareness of the human being, reducing The indiscriminate use of agrochemicals that threaten the health of those who consume the articles of the field, contribute in this way to conserve the soil and the planet earth.

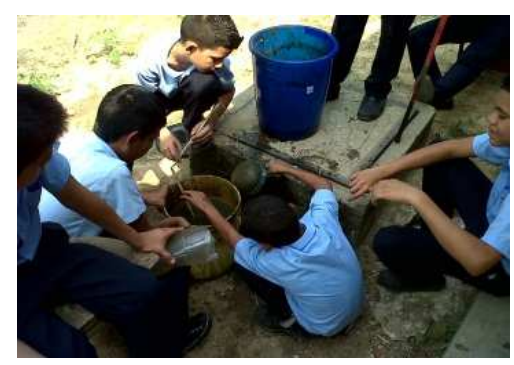

Figure 6. Casting to prevent waste entering the containers.

Therefore, secondary education integrates elements of structuring and integration of knowledge in those learning practices in the classroom and spaces for planting, in which they must be considered important in the pedagogical process to promote values with a sense of conscience and virtues in education. Young people as a fundamental pillar in academic training as "environment, integral health, interculturality, information and communication technologies and liberating work". [4], where the integrative axes will be applied as transversal axes in all learning areas, in the daily plans, they will be emphasized looking for strategies that improve the values in each of Young.

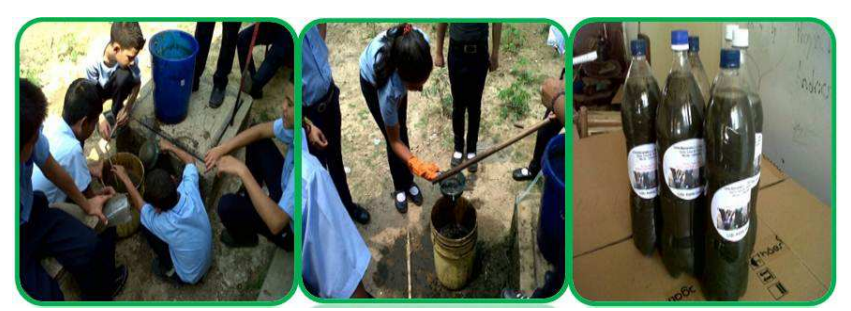

Figure 7. Packaging of agricultural Biol.

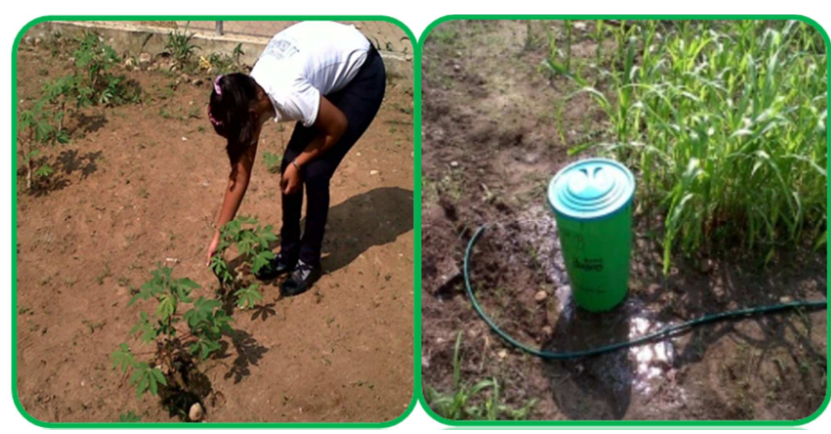

Figure 8. Plant growth, after application.

\section{Conclusions}

The development of agricultural Biol as an innovative, interesting and participatory learning strategy to improve the teaching process in the agricultural area: I help two important aspects, first: the growth of plants, foliage and leaves more resistant to insects and pests, providing minerals, nutrients to the soil and plants. Second: in the teaching process, learning improved the theme of agriculture in students, allowing a cooperative participation between each work group in the design and development of the practice, making use and benefit of the materials that are in our environment and lower production costs in products to grow.

Finally, make use and benefit of educational, recreational activities for the improvement of young people, thus becoming aware of the protection of the environment, soil and consumer health, and otherwise be retaken by the producers of the study area as a balanced alternative and be applied in the fields of work.

\section{Recommendations}

Incorporate new curricular alternatives in institutions, thus strengthening knowledge in the area of education for work and endogenous development as an educational subject, taking into account the needs of students when planning theoretical and practical activities. Develop awareness activities for teachers, students and producers on the conservation of the environment, soils, plants and the health of human beings.

For publishers, adapt textbooks to the new requirements of the ministerial curriculum and the world, aimed at preserving the environment and health. To directors, pedagogical coordinators and other educational institutions, to promote the methodological exchange full of important ideas in the educational and agricultural field; and the reflection among teachers, students and farmers, that there is integration between the institutions and the community.

At the agricultural level, recommended for coffee production, it stimulates the development of foliage and flowering of the plant. This fertilization gradually over time is losing its effectiveness; it must be used within the first three months of its development. Biol revitalizes plants that suffer stress due to pests, diseases or disruption of their normal development processes through timely, sustained and good nutrition, which offers food free of chemical residues.

\section{References}

[1] JIMENEZ, M. (2015). Pseudomonas composti sp. Nov, isolated from compost samples. Int. J. Syst Evol Microbiol. 61 (12): pp 2962-2966.

[2] CRIOLLO, H, LAGOS, T, PIARPUEZAN, E Y PÉREZ, R. (2015). Effect of three liquid biofertilizers on the production of lettuce (Lactuca sativa L.) and cabbage (Brassica oleracea L. var capitata). Colombian Agronomy 29 (3): pp 415-421.

[3] RODRÍGUEZ, R (2015). Plant physiology (online). Accessed 20-March-2015. Available at http://www.slideshare.net/fmedin1/fisiologiavegetal-5web. p21. 
[4] Bolivarian National Curriculum. Caracas - Venezuela (2007).

[5] MINISTRY OF POPULAR POWER FOR EDUCATION. (2007). Bolivarian National Curriculum. Caracas Venezuela.

[6] ORGANIC AGRICULTURE (2019). Unit of documentation and agricultural technical information INIAP, Quito-Ecuador. P 67.

[7] FERNANDO, A. (2010). Preparation and use of biol. Practical Solutions, Lima.

[8] MOSQUERA, B. (2010). Organic fertilizers. They protect the soil and guarantee healthy eating. Ecuador: Water Protection Fund (FONAG), with support from USAID. p. 5 p. 5.

[9] Info Agro. (n. d). Retrieved on January 30, 2015 from www.infoagro.com/cafe/.htm.

[10] SUQUILANDA, M. ALVARES, C. ALVARES, R. (2014): Technical guide for organic production. P 10.

[11] Agricultural Technique (n. d). Retrieved on January 25, 2019 from www.infoagro.com/bioles/abonos organicos.htm.

[12] Preparation Guide for Fermented Organic Fertilizers (2010): FASES Foundation technical team.

[13] UNIVERSITY PEDAGOGICAL EXPERIMENTAL LIBERTADOR (UPEL). (2012). Educational investigation. Caracas Venezuela.
[14] GURDIÁN A. (2007). The qualitative paradigm in socioeducational research. P 45.

[15] SABINE. C. (2008). Methods of direct investigation. Santa Fe - Colombia. P 75.

\section{Biography}

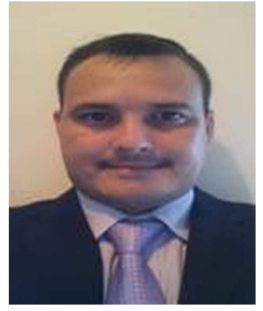

Andres Eduardo Vera Mendoza, Master in Education Mention: Educational Management; Bachelor of Education Agricultural Production Engineer; Medium Petroleum Technician. Classroom Teacher in Secondary Education: Education for Work and Health 2nd and 3rd Year. Art and Heritage 1st Year. Mathematics 1st and 2nd Year. Biology 3rd Year. Time Committee and Academic Committee. Pedagogical Coordinator Liceo B Jose Jesus Osuna Rodríguez. University Professor: Introduction to Research and Environmental Education Libertador Experimental Pedagogical University UPEL, Mérida, Venezuela. Speaker at Pedagogical Events Publications Educere Venezuela and Chakiñan Magazine-Chimborazo Ecuador. Blog Gesvin and Educar21.com.Integrante of the Editorial Committee Estoa Magazine University of Architecture and Urbanism Cuenca Ecuador. 